\title{
Trabalho de campo, narrativa e produção de conhecimento na pesquisa etnográfica contemporânea: subsídios ao campo da saúde
}

\author{
Field work, narrative and knowledge production in contemporary \\ ethnographic research: a contribution to the field of health
}

Leny Alves Bomfim Trad ${ }^{1}$

\footnotetext{
${ }^{1}$ Instituto de Saúde Coletiva, Pró-Reitoria de Pesquisa e Pós-Graduação, Universidade Federal da Bahia. Rua Basílio da Gama S/No, Canela. 40110-040 Salvador BA.trad@ufba.br
}

\begin{abstract}
In this article I reflect on the peculiarities of contemporary ethnographic research, highlighting some challenges inherent to this process. The discussion focuses in particular on the following aspects: the limits imposed by the clear reduction in immersion time in the field; the challenges in learning about ethnographic work, either in the process of observation or interaction in the field, or in the task of textual production; issues of an epistemological and ethical nature that deserve particular attention on the part of practitioners of the ethnographic approach and the scientific community in general. It is especially appropriate to foster debate around the ethnographic method, addressing its peculiarities, operational complexity and potential as a tool for knowledge production, in the sphere of health/ public health, bearing in mind the marked increase of this approach in this field.
\end{abstract}

Key words Reflexive anthropology, Ethnography in health, Field work, Narrative
Resumo Neste artigo desenvolvo um exercício de reflexão em torno das peculiaridades da pesquisa etnográfica contemporânea, assinalando alguns desafios inerentes a este processo. A discussão se centrará, especialmente, nos seguintes aspectos: os limites impostos pela notória abreviação do tempo de imersão no campo; os desafios na aprendizagem do trabalho etnográfico, seja nos processos de observação ou interação no campo, seja na tarefa de produção textual; questões de caráter epistemológico e ético que merecem uma atenção especial no por parte dos praticantes da abordagem etnográfica e da comunidade científica em geral. Considero, especialmente, oportuno promover o debate em torno do método etnográfico, abordando suas peculiaridades, complexidade operacional e potencialidades enquanto ferramenta de produção de conhecimento, na esfera da saúdel saúde coletiva, tendo em vista o incremento notável desta abordagem neste campo.

Palavras-chave Antropologia reflexiva, Etnografia em saúde, Trabalho de campo, Narrativa 


\section{Introdução}

A etnografia é reconhecida com um método central na antropologia social. Contudo, sua valorização e efetiva incorporação fazem-se notar em outros domínios disciplinares. Martinez-Hernaez ${ }^{1}$ ao reconhecer que o método etnográfico tem sido utilizado cada vez mais em outras áreas de conhecimento, além da antropologia, recorda que para empreender estudos com essa metodologia é imprescindível que o pesquisador detenha conhecimento dos fundamentos básicos da antropologia. Convém ainda distinguir a etnografia, enquanto método de pesquisa com bases teóricas específicas, da observação participante, técnica central para a coleta de dados nos estudos etnográficos.

No campo da saúde é visível o incremento de estudos que adotam o enfoque etnográfico, especialmente nas últimas décadas. Em consulta à base Scielo, adotando os descritores etnografia e método etnográfico e considerando apenas trabalhos em saúde, foram registradas 81 publicações, destas, cerca de $90 \%$ são na última década.

No rol dos pesquisadores que vem privilegiando esta abordagem na área de saúde encontramos, além de antropólogos ou sociólogos, um número expressivo de psicólogos e de profissionais de saúde de formação diversa. Um dado que é especialmente observado no campo da saúde coletiva, cujo hibridismo disciplinar constitui um traço identitário.

Neste sentido, as reflexões em torno da inserção do enfoque etnográfico na pesquisa em saúde na atualidade, devem levar em conta o perfil dos pesquisadores e, sobretudo, reafirmar a preocupação com o rigor metodológico desta etnografia cada vez mais "plural e criativa". No limite, caberia interrogar se a etnografia adotada de forma crescente na área de Saúde estaria mais próxima de observação de "tipo" etnográfico, dada as distorções que se observam das premissas originais do método ${ }^{2}$.

Por certo que as características que adquire o trabalho etnográfico nas fronteiras da saúde coletiva não derivam apenas do perfil de seus praticantes ou de traços inerentes ao campo. Muitos elementos, em princípio presentes em outros contextos disciplinares, incluindo a antropologia, refletem as transformações processadas na trajetória histórica de desenvolvimento do método enquanto ferramenta de observação, registro e interpretação de comportamentos sociais e modos de organização societais.

O trabalho de campo intensivo, levado a cabo por especialistas treinados na universidade, emer- giu como estratégia privilegiada e legitimada para obtenção de dados sobre povos exóticos desde os primórdios do século $\mathrm{XX}^{3}$. A partir da década de 1960, sobretudo nos anos oitenta, o panorama dos estudos etnográficos assumia novos contornos, revelando diferenças significativas respeito às clássicas etnografias realizadas por antropólogos como Malinovsky ${ }^{4}$, Evans Prichard ${ }^{5}$, Boas ${ }^{6}$, ou LéviStrauss ${ }^{7}$, para citar exemplos paradigmáticos.

De estudos de sociedade "totais", baseados em uma observação completa, participante e viva das sociedades estudadas ${ }^{8}$, a etnografia converte-se nos nossos dias em uma exploração muito mais modesta, centrada em uma dada temática ou aspecto específico da realidade a ser estudada. Vale remarcar que a delimitação de um foco mais preciso já era um aspecto cogitado entre antropólogos clássicos, sob o argumento de que a amplitude de uma cultura não poderia ser apreendida em uma investigação breve $e^{3}$.

A partir destes apontamentos inicias, desenvolvo ao longo deste artigo uma reflexão em torno das peculiaridades da pesquisa etnográfica contemporânea, assinalando alguns desafios inerentes a este processo. A discussão se centrará, especialmente, nos seguintes aspectos: os limites impostos pela notória abreviação do tempo de imersão no campo; os desafios na aprendizagem do trabalho etnográfico, seja nos processos de observação ou interação no campo, seja na tarefa de produção textual; questões de caráter epistemológico e ético, as quais merecem uma atenção especial por parte dos praticantes do método etnográfico e da comunidade científica em geral.

Considera-se especialmente oportuno promover o debate em torno das questões propostas na esfera da saúde/ saúde coletiva, tendo em vista o incremento já referido de estudos que adotam a abordagem etnográfica no campo.

\section{Imersão em campo: possibilidade e limitações no cenário atual de pesquisa}

A presença no campo: ver sobre o terreno, "estar lá" e voltar regularmente é a mais importante via de acesso ao conhecimento perseguido em um estudo etnográfico ${ }^{9}$. É necessário reconhecer que a qualidade das informações recolhidas e a imersão na vida diária de comunidades, de pessoas ou de instituição em um estudo etnográfico, dependem em grande medida do tempo do tempo de permanência do pesquisador no terreno de investigação.

Clifford $^{3}$, ao mencionar que desde os primórdios da etnografia havia a expectativa de que o 
etnógrafo vivesse na comunidade de estudo e permanecesse nela por tempo suficiente para o desenvolvimento do seu trabalho, ressalta que, raras vezes, tal tempo era especificado. Caberia interrogar se é possível prescrever um tempo ideal para este processo. Pode-se ponderar que a necessidade de imersão sobre o terreno é uma decisão que cada investigador toma em função das suas ideias; por conseguinte, "nenhuma receita" é válida neste caso $^{10}$.

De qualquer maneira, é razoável problematizar sobre o risco de que uma permanência muito abreviada sobre o campo tenha como resultado um conhecimento muito superficial da realidade estudada. Se participar muito pode comprometer o distanciamento necessário, participar muito pouco pode dificultar a ruptura com o olhar etnocêntrico e superficial e, sobretudo, não favorecer a compreensão a partir do interior ${ }^{11}$.

A racionalidade que orienta a produção científica nas instituições acadêmicas nos mais diversos campos, aliada ao deslocamento da etnografia para o interior da sociedade de pertença do pesquisador, são fatores que repercutem diretamente sobre o modus operandi do trabalho etnográfico. Atendo-se ao primeiro aspecto, observa-se que o tempo abreviado das etnografias pós-malinowsky decorrem em grande parte da dificuldade de pesquisadores e de estudantes de pós-graduação de viabilizar uma permanência prolongada em campo.

Dentre as dificuldades, aludidas acima, destacam-se a sobrecarga crescente de trabalho vivenciado pelos pesquisadores nos ambientes acadêmicos e a redução do tempo de conclusão de dissertações e teses, imposta pelas agências financiadoras. Em um cenário marcado pelo produtivismo acadêmico, no qual a quantidade do que se produz importa mais do que a profundidade, a consistência e a originalidade do conhecimento produzido, soa quase anacrônico um tipo de metodologia que requeira imersão prolongada no campo e maturação dos processos de análise.

Para Geertz ${ }^{12}$, um notável representante da etnografia contemporânea, de inspiração hermenêutica, realizar uma etnografia é como tentar ler (no sentido de 'construir uma leitura de') um manuscrito estranho, desbotado, cheio de elipses, incoerências, emendas suspeitas e comentários tendenciosos, escrito não com os sinais convencionais do som. A leitura e a tradução deste "manuscrito borrado" oferecem a cada momento novas possibilidades. Neste sentido, pode-se argumentar que qualquer que seja o ponto de interrupção do trabalho de campo, os dados gerados serão sem- pre parciais. Por outro lado, é preciso reconhecer que este processo de 'leitura' da realidade observada, pode ser mais ou menos superficial, mais ou menos coerente.

É imprescindível enfatizar ainda que a discussão sobre o tempo de permanência no trabalho de campo deve considerar sempre a intensidade e a consistência das interações processadas entre o pesquisador e seus informantes. Uma maior ou menor oportunidade do pesquisador de acercar-se ao universo pesquisado, ou de explorar situações ou informações vinculadas ao objeto de estudo, bem como sua habilidade para apreender e traduzir o observado ou dito, são aspectos que incidirão sobre a qualidade do produto etnográfico. Além disso, é importante considerar também outros recursos que o pesquisador pode dispor 'fora' do campo. As notas de campo não são a única fonte de informação disponível sobre o tema ou objeto de estudo ${ }^{13}$.

\section{O trabalho etnográfico: um aprendizado necessário}

A definição do etnógrafo como uma figura quase mítica pode ser claramente apreendida nas palavras de Levis Strauss ${ }^{7}$ em "Tristes trópicos": sempre se considerando humano, o etnógrafo procura conhecer e julgar o homem de um ponto de vista elevado e distante o suficiente para abstraí-lo das contingências próprias a esta sociedade ou àquela civilização. Ele complementa sua aposta no caráter vocacional da etnografia, ao reconhecer nesta uma das raras vocações autênticas. Podemos descobri-la em nós, ainda que não nos tenha sido ensinada por ninguém. Esta imagem contrasta com a visão de um etnógrafo forjado a custa de treinamento e de formação, a qual representou uma ruptura com a etnografia realizada pelos missioneiros e expedicionários.

Clifford ${ }^{3}$ destaca que algumas inovações institucionais e metodológicas contribuíram para que a etnografia levada a cabo por especialistas ganhasse força a partir da década de 1920. Imprime-se a partir de então a valorização tanto pública quanto profissional da figura do etnógrafo profissional. Um tipo treinado em técnicas modernas de análise e diferentes modalidades de explicação científica. Tais habilidades, ressalta o autor, o distinguia de missioneiros, administradores e outros cuja visão dos nativos era, presumivelmente, mais comprometida.

A preocupação com o desenvolvimento de habilidades específicas para a realização do trabalho etnográfico rigoroso é reafirmada na con- 
temporaneidade por diferentes autores. Laplantine ${ }^{9}$ recorda que o exercício competente dos processos de olhar e de escutar na prática etnográfica do investigador é resultado de um processo de aprendizagem. Um tipo de aprendizagem que deveria ser contemplada por um programa específico de formação.

Pensando em termos de uma formação disciplinar, esta conformaria um projeto conceitual que se reflete diretamente sobre a maneira de cada investigador ver a realidade que observa; melhor dito, a maneira na qual o seu objeto de estudo é apreendido ${ }^{8}$. Contudo, quando consideramos o perfil dominante entre pesquisadores que desenvolvem estudos etnográficos na área de saúde, particularmente da saúde coletiva, encontramos um modo de "ver a realidade" ou uma "formação" que refletem a interpenetração de conhecimentos biomédicos, instrumentais, sociais etc. Neste sentido, um dos grandes desafios para a formação em pesquisa de base antropológica, notadamente de tipo etnográfica, consiste no desenvolvimento da capacidade dos pesquisadores em definir e apreender referenciais teórico-conceituais adequados ao seu estudo, os quais devem modular "a observação, a percepção e a interpretação do pesquisador em todas as fases da pesquisa" ${ }^{14}$.

Observa-se, ao mesmo tempo, que certas peculiaridades do campo da saúde podem potencializar a adoção do enfoque etnográfico. Schimit ${ }^{15}$ reconhece na saúde um campo fértil para a prática etnográfica, identificando em seus domínios um território propício à formação ética $\mathrm{e}$ especializada nesta abordagem. Ela sugere um programa de formação (desde a graduação, iniciação científica) que alie o ensino teórico à aprendizagem experiencial da etnografia. Insere-se aqui uma conjunção de estratégias que contempla disciplinas específicas e um conjunto de atividades que caracterizam o treino de pesquisa (seminários, orientação, prática de trabalho de campo).

Um dos grandes desafios para essa pretendida formação reside no fato, enfatizado por Peirano $^{16}$, da impossibilidade de ensinar etnografia como se esta fosse apenas uma técnica. Seu aprendizado, salienta a autora, é um processo que se realiza através da experiência vivenciada e acumulada em Campo e, sobretudo, das reflexões produzidas no percurso realizado.

O fato é que, tanto no elenco daquilo que pode ser ensinado, quanto de outro, que reúna aquilo que só se aprende pela experiência, não poderá faltar considerações relativas à tríade olhar, ouvir e escrever, posto que reside ai o percurso essencial do trabalho etnográfico. Para Cardoso de Olivei$\mathrm{ra}^{8}$, o nosso saber é construído a partir da articulação destes três atos cognitivos de natureza epistêmica: se nossa percepção se realiza através do olhar e do ouvir "disciplinado" pela disciplina, é no ato de escrever que o pensamento é exercitado como produtor de um discurso. Acrescenta-se ainda que, se a escuta pode esclarecer aquilo que o olhar registrou, será preciso compreender o sentido de cada visão ou palavra ${ }^{8}$.

No que diz respeito à escuta, é importante reconhecer as múltiplas oportunidades para o seu exercício no decorrer da observação participante, evitando assim restringir este processo aos momentos de entrevistas formais, uma tendência recorrente em estudos que referem à adoção da etnografia no campo da saúde coletiva. Em certa medida, tal limitação foi observada em um dos estudos que realizei no campo da saúde ${ }^{17}$, o qual seria mais bem qualificado como uma pesquisa de cunho etnográfico.

Para ilustrar os limites da entrevista, quando comparada ao exercício mais amplo da observação em campo, Binet ${ }^{18}$ descreve uma situação em que o objeto de estudo consiste na prática profissional do assistente social. De imediato, ele reconhece que a entrevista com assistentes sociais abordando sua prática profissional permitiria recolher narrativas sobre o tema, cujas análises poderiam ser enriquecidas através da triangulação com outras fontes. Em seguida, ele pondera que os dados apreendidos por esta via conformariam um corpus de alcance limitado.

$\mathrm{O}$ autor argumenta que o discurso sobre a prática profissional no contexto descrito (recolhido através de entrevista) foi gerado fora do contexto real em que ele se realiza. Perdem-se por esta via, muitos "aspectos e detalhes que só uma observação in situ permite capturar". Cabe reiterar que a observação participante constitui a principal estratégia metodológica da etnografia.

Para concluir esta seção, acrescento algumas considerações a respeito da escrita. A antropologia de base reflexiva e pós-moderna tem destinado especial interesse aos processos textuais e narrativos. O que é curioso se considerarmos que, durante um bom tempo, os antropólogos não pensaram muito em "narrativa"; a monografia antropológica mantinha-se, há décadas, fiel a um formato razoavelmente uniforme e aparentemente natural ${ }^{19}$. Em tempos pós-modernos ou reflexivos, os etnógrafos são convocados a produzir narrativas que considerem, entre outros aspectos, a dimensão histórica da realidade social, os limites inerentes ao processo de descrição do 
observado ou escutado, os dilemas éticos em torno da autoridade ou da autoria etc., ${ }^{3,19}$.

Admite-se, então, que a descrição etnográfica é antes redescrição de uma realidade, cujo investigador, através do ato da escrita, assume o papel de intérprete ou de tradutor ${ }^{9}$. A credibilidade do texto etnográfico neste contexto dependeria menos da amplitude das descrições, e mais da capacidade do autor em convencer aos que não compartilharam com ele da experiência de campo, de que ele efetivamente esteve ali e conseguiu penetrar (ou ser penetrado) e apreender o modo de vida do grupo em questão ${ }^{20}$.

À medida que as pretensões realistas da etnografia clássica foram postas em cheque, as narrativas contemporâneas esforçam-se em realçar o caráter polifônico das experiências e das situações coletivamente compartilhadas. Requer-se ainda que os manuscritos problematizem limites e contradições associadas às eventuais diferenças de classe, de padrões culturais ou de capital político entre o investigador e o grupo ou a sociedade estudada.

\section{Implicações epistemológicas e éticas da etnografia: 'falar com', 'falar de', produzir conhecimento}

É necessário sempre distinguir a descrição etnográfica do texto literário, bem como, do jornalístico. Peirano ${ }^{16}$ alerta sobre o risco de transformar o texto etnográfico em um conjunto de descrições que privilegiam os aspectos mais bizarros ou exóticos que o investigador encontrou sobre o terreno. Ela rechaça uma concepção empiricista da etnografia, cujo produto limita-se à mera descrição de depoimentos, por mais criativa que esta resulte. Convém, portanto, desmistificar a "crença de que a criatividade pode superar a falta de disciplina e a carência de um ethos científico" ${ }^{16}$.

$O$ processo de refinamento de problemas e conceitos, enfatiza Peirano ${ }^{16}$, implica adotar duas perspectivas complementares. Uma que reconhece a especificidade do caso concreto investigado. Outra que busca apreender o caráter universal da sua manifestação. Usando termos semelhantes, Laplantine 9 salienta que a descrição etnográfica deve responder à exigência de globalidade, realizando um duplo movimento: ligar o fenômeno estudado à totalidade social na qual se inscreve e, ao mesmo tempo, compreender as suas dimensões específicas.

Os limites da descrição descontextualizada de processos referentes a uma dada sociedade ou grupo social, sejam estes rituais ou outros atos sociais, são também referidos por Segalen ${ }^{21}$. Tomando de empréstimo as considerações de Van Gennep, a autora critica, particularmente, a ausência da análise em torno das relações que se estabelecem entre os vários elementos que compõe as cenas, as situações descritas:

Um rito ou um acto social não tem valor nem sentido intrínsecos constantes; muda de valor e de sentido de acordo com os actos que o precedem e com os que o seguem; de onde se conclui que para compreender um rito, uma instituição ou uma técnica, não devemos extraí-lo arbitrariamente do conjunto cerimonial, jurídico ou tecnológico em que está inserido; mas, pelo contrário, é sempre necessário considerar cada elemento deste conjunto nas suas relações com todos os outros elementos ${ }^{21}$.

$\mathrm{O}$ etnógrafo observa e paralelamente interpreta. Seleciona do contexto o que há de significativo em relação à elaboração teórica que está realizando. Cria hipótese, realiza uma multiplicidade de análises, reinterpreta, formula novas hipóteses ${ }^{22}$.

Não se trata apenas de entender o indivíduo enquanto indivíduo, mas sim os processos que fabricam o social, seu mundo social em torno deste processo ${ }^{23}$. A vigilância epistêmica no trabalho etnográfico consiste em equilibrar a valorização da subjetividade com o imperativo de produzir conhecimento científico. A interação no campo não é neutra, ela se confronta sempre com a realidade objetiva que é pensada, expressa, comprimida pelas pessoas segundo os termos de sua cultura; deste modo é necessário investigar as contradições entre os informantes e considerar a manipulação que possam fazer dos dados, revendo ao mesmo tempo as nossas próprias impressões e interpretações ${ }^{23}$.

Parte das preocupações e questões apontadas acima comporta, necessariamente, dimensões éticas que não dizem respeito apenas à pesquisa etnográfica. Mas, atendo-se a esta última, ressaltase o risco de que o deslocamento da etnografia para terrenos próximos do investigador, o leve a subestimar as diferenças culturais e de poder entre ele e os seus entrevistados. As mudanças e/ou multiplicação dos territórios de pesquisa não tornaram mais fácil a tarefa de inserir o outro no produto final da etnografia. Seja no campo convencional ou no novo, mantém-se a questão de como falar do outro de uma maneira que permita conciliar, no mesmo texto, o caráter íntimo e subjetivo da experiência no campo com as dimensões analíticas ligadas aos enunciados que ele porta ${ }^{13}$.

A preocupação com a construção de uma etnografia dialógica e polifônica começa no mes- 
mo momento que o investigador chega ao seu terreno; melhor dito, no momento que ele escolhe o seu objeto de estudo ${ }^{23}$. Nesta direção, revela-se oportuna a proposta de redefinir a posição, relativamente passiva, do informante. Cardoso de Oliveira ${ }^{8}$ sugere um tipo de enquadre para o relacionamento entre o pesquisador e o sujeito, o grupo ou a comunidade investigada, no qual "o ouvir ganha uma qualidade que altera a relação, de uma estrada em mão única para uma de mão dupla, portanto uma verdadeira interação".

Detendo-se inicialmente na etapa de campo, encontramos em Schmidt ${ }^{15}$ a descrição de algumas atitudes que expressariam o compromisso ético do pesquisador. A saber: busca de interlocução e de diálogo no trabalho de campo visando compreender o sentido e os significados da experiência de outros próximos ou distantes; distribuição democrática de lugares de escuta, fala e decisão entre pesquisador e colaboradores ou interlocutores; disposição para negociar e refazer os contratos ou pactos de trabalho compartilhado entre pesquisador e colaborador sempre que necessário; empenho no esclarecimento, fidelidade, respeito e solidariedade às formas de viver desenhadas pelos colaboradores e cuidado em sua transcrição em texto.

As preocupações de caráter ético não se restringem ao momento do trabalho de campo. Deve incluir necessariamente o produto que dele deriva e que é publicizado. Como advertiu Geertz ${ }^{20}$, "uma vez que se passa a olhar para os textos etnográficos, além de através deles, uma vez que eles são vistos como objetos produzidos, e produzidos para persuadir, aqueles que os produzem têm muito mais pelo que se responsabilizar".

Schmidt ${ }^{15}$ reconhece que os efeitos políticos e ideológicos da divulgação e da recepção de uma pesquisa não podem ser planejados ou controlados pelo pesquisador. Mas, ressalta a necessidade de antever e de ponderar os eventuais efei- tos daquilo que é publicizado. Para minimizar os limites inerentes à tarefa de interpretar e de traduzir vidas alheias, tarefa por excelência da etnografia, Godelier ${ }^{23}$ recomenda como atitude metódica da pesquisa de campo realizar, sempre que possível, a revisão conjunta com os colaboradores de transcrições de relatos orais e de observações, bem como de textos interpretativos.

Para concluir, recorro primeiro a Price ${ }^{19}$, compartilhando com ele as seguintes inquietações: como encontrar o caminho para chegar ao complicado relacionamento entre fato e ficção, verdade e fantasia, passado e presente, trabalho de campo e memória em nossos relatos etnográficos, ao mesmo tempo em que permanecemos comprometidos com aqueles sobre quem escrevemos? Ou ainda, como atender aos apelos dessa "nova" etnografia que pressupõe reflexividade, contextualização, envolvimento ético e político, ao tempo que joga o leitor de um lado para o outro no tempo e no espaço?

Ressalto ainda que as pretensões de formação do etnógrafo, seja no campo da saúde ou alhures, se defronta com um aspecto paradoxal em torno da etnografia. Qual seja: de que seu aprendizado se realiza efetivamente através do exercício prático. Sendo também razoável supor que parte de seu êxito depende da maior ou menor sensibilidade/habilidade do pesquisador nos processos de interação, escuta e observação em campo. Mas, ao mesmo tempo, a ausência de uma formação mais consistente em torno das bases teóricas e epistemológicas que dão sustentação ao método etnográfico, bem como de interlocuções com pesquisadores mais experientes que possam assumir, em certos casos, uma posição de supervisão, pode comprometer fortemente sua validade. Assim sendo, convém vislumbrar estratégias de formação na abordagem etnográfica que combinem duas experiências de imersão: na esfera teóricoconceitual e no campo. 


\section{Referências}

1. Martinez-Hernaez A. Dialógica, etnografia e educação em saúde. Rev Saude Publica 2010; 44(3):399-405.

2. Caprara A, Landim LP. Etnografia: uso, potencialidades e limites na pesquisa em saúde. Interface Comun Saúde Educ 2008; 12(25):363-376.

3. Clifford J. Sobre la autoridad etnográfica. In: Reynoso C, organizador. El surgimiento de la antropologia pos-moderna. Barcelona: Gedisa; 2003. p. 141-170.

4. Malinovsky B. Argonautas do Pacífico Ocidental. Rio de Janeiro: Abril Cultural; 1991.

5. Evans-Prichard E. Os Nuer. São Paulo: Perspectiva; 1978.

6. Boas F. The Central Esquimo. Lincoln: University of Nebraska Press; 1964.

7. Lévi-Strauss C. Tristes tropiques. Paris: Plon; 1955.

8. Cardoso de Oliveira R. O trabalho do antropólogo. Brasília, São Paulo: Paralelo XV, Ed UNESP; 2000.

9. Laplantine F. La description ethnographique. Paris: Armand Colin; 2005.

10. Fainzang S. De l'autre cote du miroir. Réflexions sur l'ethnologie des anciens alcooliques. In: Ghasarian C, organizador. De l'ethnographie à l'anthropologie réflexive. Paris: Armand Colin; 2004. p. 63-71.

11. Ghasarian C. Sur les chemins de l'ethnographie réflexive. In: Ghasarian C, organizador. De l'ethnographie à l'anthropologie réflexive. Paris: Armand Colin; 2004. p. 5-34.

12. Geertz C. A interpretação das culturas. Rio de Janeiro: LTC; 1989.

13. Bellier I. Du lointain au proche. Réflexions sur le passage d'un terrain exotique au terrain des institutions politiques. In: Ghasarian C, organizador. De l'ethnographie à l'anthropologie réflexive. Paris: Armand Colin; 2004. p. 45-62.
14. Nakamura E. O método etnográfico em pesquisas na área da saúde: uma reflexão antropológica. Saúde e Sociedade 2011; 20(1):95-103.

15. Schmidt MLS. Pesquisa participante e formação ética do pesquisador na área da saúde. Cien Saude Colet 2008; 13(2):391-398.

16. Peirano M. A favor da etnografia. Rio de Janeiro: Relume-Darumá; 1995.

17. Trad LAB, Bastos ACS, Santana EM, Nunes AO. Estudo etnográfico da satisfação do usuário do Programa de Saúde da Família (PSF) na Bahia. Cien Saude Colet 2002; 7(3):581-589.

18. Binet M. Etnográfia e Análise da Conversação: Convergências e Orientações de pesquisa. Documento de Trabalho do GIID nº4. Lisboa: FCSH-UNL; 2010.

19. Price R. Meditação em torno dos usos da narrativa na antropologia contemporânea. Horiz. Antropol. 2004; 10(21):293-312.

20. Geertz C. Works and Lives: The Anthropologist as Author. Stanford: Stanford University Press; 1988.

21. Segalen M. Ritos e rituais contemporâneos. Rio de Janeiro: FGV Editora; 2000.

22. Rockwell E. Ethnography and critical knowledge of education in Latin America. Prospects 1986; 21(2): 156-167.

23. Godelier M. Briser le miroir du soi. In: Ghasarian C, organizador. De l'ethnographie à l'anthropologie réflexive. Paris: Armand Colin; 2004. p. 193-212.

Apresentado em 05/09/2011

Aprovado em 01/12/2011

Versão final apresentada em 06/12/2011 